\title{
Lavagem traqueobrônquica por sondagem nasotraqueal em bezerros
}

\author{
[Tracheobronchial lavage in calves using a nasotracheal technique] \\ R.C. Gonçalves ${ }^{1}$, M.C.F.I. Mattos ${ }^{2}$, M.R.G. Kuchembuck ${ }^{1}$, R.S. Lopes $^{1}$, A.S. Borges ${ }^{1}$ \\ ${ }^{1}$ Faculdade de Medicina Veterinária e Zootecnia - UNESP \\ Distrito de Rubião Junior, $\mathrm{s} / \mathrm{n}$ \\ 18618-000 - Botucatu, SP \\ ${ }^{2}$ Faculdade de Medicina - UNESP - Botucatu
}

\section{RESUMO}

Avaliou-se a técnica de lavagem traqueobrônquica por sondagem nasotraqueal e caracterizou-se a população celular em 10 bezerros clinicamente sadios. Após a contenção dos animais em decúbito lateral e auxílio de sonda guia, foi introduzida uma sonda de menor diâmetro até a bifurcação da traquéia, para produzir tosse e obter o lavado traqueobrônquico. A média de células totais nas amostras de lavado foi de 133.750 células $/ \mathrm{ml}$. À citologia, foram observados na contagem diferencial: 77,2\% macrófagos, 14,9\% células epiteliais cilíndricas, 6,0\% neutrófilos e 1,8\% linfócitos. Das células epiteliais cilíndricas, 79,0\% eram do tipo ciliadas e 21,0\% não-ciliadas. A média de contagem de macrófagos binucleados foi de 78,5 células/lâmina, a de macrófagos trinucleados de 20,5/lâmina e a de células gigantes 28,5/lâmina. Concluiu-se que o método de colheita por sondagem nasotraqueal é eficiente para caracterizar a citologia do lavado traqueobrônquico de bezerros clinicamente sadios.

Palavras-chave: bezerro, lavado traqueobrônquico, citologia

\begin{abstract}
Tracheobronchial lavage through nasotracheal via was performed in 10 clinically health calves. They were maintained in lateral recumbence to perform the procedure. A small tube inserted into a guide tube was introduced until the tracheal bifurcation, producing cough, facilitating the collection of the lavage fluid. The mean number of total cells present in the samples was 133,750 cells $/ \mathrm{ml}$. The differential counting was represented by $77.2 \%$ of macrophages, $14.9 \%$ of cylindrical epithelial cells, $6.0 \%$ of neutrophils, $1.8 \%$ of lymphocytes. The cylindrical ciliated cells represented $79.0 \%$ of the sample and the nonciliated cells represented $21.0 \%$. The mean number of macrophages was 78.5 of binucleated cells, 20.5 of trinucleated cells, and 28.5 of giant cells per smear. The tracheobronchial lavage obtained by this technique was an efficient method to characterize the cytological population of the lungs of clinically health calves.
\end{abstract}

Keywords: calf, tracheobronchial lavage, cytology

\section{INTRODUÇÃO}

$\mathrm{Na}$ avaliação do aparelho respiratório, além do exame clínico, destacam-se alguns procedimentos complementares, necessários tanto para o diagnóstico como para a estimativa

\begin{abstract}
de sua gravidade. Entre os exames complementares, a colheita do lavado traqueobrônquico tem sido associada ao diagnóstico clínico, para realização do diagnóstico etiológico e do prognóstico.
\end{abstract}

Recebido para publicação em 3 de janeiro de 2003

Recebido para publicação, após modificações, em 4 de fevereiro de 2004

E-mail: calderon@fmvz.unesp.br 
Gonçalves (1987), ao trabalhar com lavado traqueal por traqueocentese em bezerros sadios e portadores de broncopneumonia bacteriana, verificou que esse recurso diagnóstico contribuiu para identificar a etiologia e estabeleceu o baixo risco dessa técnica associado à facilidade de aplicação do método pelos profissionais no campo.

A literatura mostra o empenho de vários autores no sentido de viabilizar a colheita do lavado traqueobrônquico. A aspiração ou lavagem da traquéia por traqueocentese foi inicialmente proposta por Mansmann e Knight (1972). Várias adaptações da técnica inicial foram desenvolvidas em bovinos, entre elas a lavagem traqueobrônquica por traqueocentese (Gonçalves et al., 1990; Barros et al., 1994), a lavagem bucotraqueal (Corstvet et al., 1982), a lavagem broncoalveolar às cegas (Taylor et al., 1989) e a lavagem broncoalveolar por endoscopia (Allen et al., 1992). Em eqüinos, a intubação nasotraqueal foi empregada no estudo citológico dos pulmões, utilizando-se um tubo de PVC flexível como guia e um tubo de polipropileno adaptado à uma seringa, pelo qual foram injetadas e aspiradas seis alíquotas de $50 \mathrm{ml}$ de solução fisiológica para colheita do lavado broncoalveolar. Essas amostras, obtidas de bronquíolos e de espaços aéreos terminais, refletiram a população celular do epitélio das vias aéreas e do revestimento alveolar (Crisman et al., 1992), pela quantidade de células e a presença de macrófagos alveolares (Zink1, 1992).

Apesar da concordância dos vários autores sobre as exigências metodológicas do estudo do lavado traqueobrônquico, existe controvérsia na escolha do método ideal para obtenção das amostras. Segundo Derksen et al. (1989), a lavagem traqueal não é a melhor alternativa para o estudo citológico dos pulmões de bezerros, pois além de não fornecer grande número de células, as epiteliais cilíndricas predominam nesse tipo de lavado e a população de macrófagos é pequena. Associa-se, também, o fato de que a punção da traquéia é pouco aceita pelos criadores, especialmente nos bezerros sadios. A despeito da inocuidade do procedimento ter sido comprovada em alguns estudos (Gonçalves et al., 1990; Barros et al., 1994), são relacionados fatores desfavoráveis como celulite no local da punção, condrite e pneumomediastino (Hoffman et al., 1993). Embora raros, foram assinalados casos de hemorragia e hemoptise (Hoffman et al., 1993), confirmados pela presença de células sanguíneas nas amostras obtidas (Roszel et al., 1986).

Considerando a importância do diagnóstico precoce das broncopneumonias em bezerros e a necessidade de um método diagnóstico complementar, de baixo custo e de fácil aplicação no campo, o objetivo deste trabalho foi testar o método de lavagem traqueobrônquica por intubação nasotraqueal em bezerros sadios.

\section{MATERIAL E MÉTODOS}

Foram utilizados 10 bezerros clinicamente sadios independentemente de raça e sexo, com idades entre um e seis meses. Eles foram contidos em decúbito lateral, com a cabeça e o pescoço sobre um campo cirúrgico estéril. Após esse procedimento, foi introduzido, por via nasotraqueal, um tubo guia siliconizado de $1,1 \mathrm{~cm}$ de diâmetro e $65 \mathrm{~cm}$ de comprimento, previamente imerso em solução aquosa de polioctil-poliamino-etilglicina e polióxi-etilenoalquilfenol-eter ${ }^{1}$, na diluição de 1:200 (Torres et al., 1970), embalado individualmente e seco em câmara de esterilização por raio ultravioleta. Por dentro do tubo guia foi introduzida uma sonda de polietileno com $3,5 \mathrm{~mm}$ de diâmetro e $100 \mathrm{~cm}$ de comprimento, adaptada a uma agulha calibre 30 , sem bisel, até aproximadamente a bifurcação da traquéia, para produzir tosse. O conjunto sonda de polietileno e agulha foi previamente tratado na solução descrita acima, permanecendo imerso por tempo mínimo de 15 minutos. Imediatamente antes da introdução, o conjunto foi lavado com $20 \mathrm{ml}$ de solução salina isotônica, estéril comercial.

Após a sondagem nasotraqueal, a amostra foi colhida por método de lavagem traqueobrônquica (Gonçalves et al., 1990), utilizando-se uma seringa estéril de vidro, com capacidade de $100 \mathrm{ml}$, adaptada ao conjunto, onde foram injetados e, imediatamente, aspirados $60 \mathrm{ml}$ de solução salina isotônica, comercial, estéril e apirogênica. $\mathrm{O}$ lavado traqueobrônquico obtido foi acondicionado em tubo de ensaio de polietileno e enviado ao laboratório de citologia, no tempo máximo de duas horas.

\footnotetext{
${ }^{1}$ OBANOL - 516 - FATEC Ltda.
} 
Para a contagem total de células, o lavado foi homogeneizado em agitador de tubos ${ }^{2}$, por 10 segundos. Em seguida, misturaram-se 900 microlitros do lavado a 100 microlitros de uma solução corante de cristal violeta. O número total de células por mililitro foi contado em câmara de Neubauer, em analogia com a técnica descrita para a contagem de leucócitos (Jain, 1993). A média dos quatro cantos da câmara, multiplicada por $10^{4}$, forneceu o número total de células por mililitro de lavado. Para a impressão celular de $6 \mathrm{~mm}$ de diâmetro em lâminas de vidro, foi realizada citocentrifugação ${ }^{3}$ de 200 microlitros do lavado traqueobrônquico a 189 x $g$ por cinco minutos.

Para coloração pelo método de Shorr, as células foram fixadas com solução de álcool etílico a $90 \%$. Para as demais colorações, Giemsa, Gomori-Grocott, Ziehl-Nielsen e Gram, a fixação das células se deu por secagem ao ar ambiente (Koss, 1992).

Realizou-se a contagem diferencial de células, avaliando-se a porcentagem de células epiteliais cilíndricas (CEC), macrófagos (M), neutrófilos (N), linfócitos (L) e eosinófilos (E). Para isso, foram contadas 400 células em microscópio óptico comum, em aumento de 400 vezes, utilizando-se as colorações de Shorr e Giemsa. Entre as células epiteliais cilíndricas foram contadas em toda a lâmina, excluindo-se os aglomerados celulares, as células epiteliais cilíndricas ciliadas (CEC) e as não-ciliadas (CENC), estabelecendo-se a proporção entre elas. Utilizou-se, para isso, a coloração de Shorr. Nas colorações de Shorr e Giemsa foram contados, em toda a lâmina, o número total e proporcional de macrófagos binucleados, trinucleados e os que apresentavam mais de três núcleos, chamados de células gigantes. Nas lâminas que apresentaram muitos aglomerados celulares, a contagem diferencial foi feita, preferencialmente, na periferia.

\section{RESULTADOS E DISCUSSÃO}

Os bezerros suportaram bem o método de colheita, não houve necessidade de sedação e o método forneceu material adequado para 0

${ }^{2}$ PHOENIX - MOD. AT 56

${ }^{3}$ CYTOSPIN - SHANDON ELLIOT exame citológico. Ele mostrou-se seguro e prático, atingindo o objetivo de obter amostras de regiões pulmonares mais profundas. Uma amostra de lavado, representativa das regiões pulmonares mais profundas, é aquela constituída por grande quantidade de macrófagos alveolares e pouca contaminação por células do trato respiratório anterior (Zinkl, 1992). Com esse método de colheita, adaptado de Crisman et al. (1992), os lavados obtidos foram ricos em macrófagos alveolares, raramente contaminados.

O tubo guia utilizado neste trabalho foi eficiente para evitar a contaminação por células da orofaringe e da traquéia, o que costuma ocorrer nos lavados bucotraqueais (Corstvet et al., 1982). Pela necessidade do lavado representar o máximo possível dos pulmões, o líquido foi depositado na bifurcação traqueal, evitando-se a limitação provocada pela lavagem broncoalveolar às cegas, realizada com a introdução do tubo guia no brônquio (Taylor et al., 1989) ou por endoscopia bronquial (Allen et al., 1992). A introdução dos tubos contribuiu, também, para desencadear o reflexo de tosse, favorecendo a colheita de células das regiões mais profundas (Roszel et al., 1986).

Apesar da literatura apresentar vários resultados citológicos de lavados pulmonares de animais sadios e doentes, a metodologia de colheita bastante variada, e as condições patológicas nem sempre uniformes, dificultam a comparação dos achados e, por conseqüência, a diferenciação entre o normal e o alterado. Nesse sentido, são essenciais a especificação precisa dos aspectos avaliados e o reconhecimento das limitações metodológicas que possam interferir nos resultados.

O número total de células do lavado traqueobrônquico ou broncoalveolar em eqüinos é um dado duvidoso para interpretação do caso clínico, pela grande variação observada (Sweeney e Smith, 1990). A observação individual da celularidade do lavado traqueobrônquico revelou pequena variação no número total de células, atingindo um máximo de 185.000 células por mililitro sendo a média encontrada de $133.750 \pm 51.496,36$. A contagem total e diferencial das células do lavado traqueobrônquico, obtida neste trabalho, encontra-se na Tab. 1. 
Tabela 1. Contagem total e diferencial das células do lavado traqueobrônquico de bezerros sadios

\begin{tabular}{lc}
\hline Total & $133.750 \pm 51.496,36$ \\
\hline Macrófagos & $77,2(\%)$ \\
Células epiteliais & $14,9(\%)$ \\
Neutrófilos & $6,0(\%)$ \\
Linfócitos & $1,8(\%)$ \\
Eosinófilos & $0,0(\%)$ \\
\hline
\end{tabular}

$\mathrm{Na}$ contagem diferencial, o lavado traqueobrônquico caracterizou-se por alta porcentagem de macrófagos, seguida por células epiteliais cilíndricas, neutrófilos, e linfócitos, e não se observaram eosinófilos Ao trabalhar com lavagem broncoalveolar por via endoscópica, Currle (1985) demonstrou, em bezerros sadios, predomínio da população de macrófagos (59,2\%), seguida de $32,4 \%$ de células epiteliais cilíndricas, $6,5 \%$ de neutrófilos e pequena quantidade linfócitos e eosinófilos $(0,8 \%)$, à semelhança dos achados deste trabalho.

Dependendo do local da colheita do lavado, a população de células se diferencia no lavado obtido. Na amostra traqueal predominam células epiteliais cilíndricas (Derksen et al., 1989) e no lavado traqueobrônquico ou broncoalveolar de bezerros clinicamente sadios, o encontro de grande número de macrófagos caracteriza amostragem adequada das partes mais profundas do pulmão (Derksen et al., 1989). Os resultados deste trabalho confirmam esse raciocínio, associado aos dados de observações anteriores, em animais clinicamente sadios (Sweeney et al., 1992; McGorum et al., 1993)

Os macrófagos podem se juntar para englobar e destruir agentes estranhos, formando sincícios que limitam o agressor. Essa propriedade das células fagocitárias está relacionada à diferenciação dos macrófagos quando, numa mesma célula, podem ser observados vários núcleos. A presença de dois, três ou mais núcleos caracteriza, respectivamente, os macrófagos bi, trinucleados e as células gigantes (Sweeney et al., 1992; Zinkl, 1992). Essas observações foram comprovadas neste trabalho pelo encontro de diferentes percentuais de macrófagos binucleados, trinucleados e células gigantes (Tab. 2). A porcentagem de macrófagos varia de 50 a $90 \%$ em bovinos ou eqüinos sadios nas colheitas brônquicas às cegas (Sweeney et al.,
1989) ou por endoscopia (Sweeney et al., 1992; McGorum et al., 1993), valores semelhantes aos obtidos neste trabalho.

Tabela 2. Células ciliadas, não-ciliadas, macrófagos bi e tri-nucleados e células gigantes contados em toda a lâmina de lavado traqueobrônquico de bezerros sadios

\begin{tabular}{ll}
\hline Células epiteliais ciliadas & $79,0(\%)$ \\
Células epiteliais não-ciliadas & $21,0(\%)$ \\
Macrófagos binucleados & $61,7(\%)$ \\
Macrófagos trinucleados & $15,8(\%)$ \\
Células gigantes & $22,5(\%)$ \\
\hline
\end{tabular}

A literatura descreve pequena quantidade de células epiteliais cilíndricas variando de $0,3 \%$ (McGorum et al., 1993) ou 0,6\% (Sweeney et al., 1992) a, no máximo, 2,2\% (Pringle et al., 1988). Neste experimento, apesar da baixa percentagem de células epiteliais cilíndricas (Tab. 1), elas eram, na sua maioria, ciliadas (Tab. 2), refletindo a integridade do sistema de limpeza mucociliar. O desarranjo celular pode levar à perpetuação da lesão sobre o epitélio, diminuindo a ação da defesa pulmonar e, por conseqüência, facilitar a penetração de agentes infecciosos (Scott, 1994).

Sabe-se que os neutrófilos são as células de defesa mais mobilizadas na inflamação (Leid e Potter, 1985). Nos animais clinicamente sadios, elas apresentam contagem (percentual) relativamente baixa, fato registrado neste trabalho, à semelhança de outros autores (Pringle et al., 1988; Allen et al., 1992). Os macrófagos constituíram a maior porcentagem de células (Tab. 1).

A maioria dos trabalhos, à semelhança deste, confirma ausência ou pequena proporção de eosinófilos no lavado traqueobrônquico de eqüinos e bovinos clinicamente sadios ou portadores de doenças respiratórias (Currle, 1985; Derksen et al., 1989; McGorum et al., 1993). O encontro de eosinófilos pode estar relacionado a reações provocadas por dictiocaulose ou fungos (Lester, 1993) ou à fase alérgica da doença pulmonar obstrutiva crônica (Deegen et al., 1982).

O método de colheita por sondagem nasotraqueal, com tubo auxiliar introduzido próximo à bifurcação da traquéia, além da vantagem de poder ser usado no campo, 
mostrou-se eficiente na amostragem celular do lavado traqueobrônquico de bezerros. Recomenda-se, portanto, seu uso como adjuvante no estudo do aparelho respiratório de bezerros.

\section{REFERÊNCIAS BIBLIOGRÁFICAS}

ALLEN, J.W.; VIEL, L.; BATEMAN, K.G. et al. Cytological findings in bronchoalveolar lavage fluid from feedlot calves: associations with pulmonary microbial flora. Can. J. Vet. Res., v.56, p.122-126, 1992.

BARROS, M.S.R.M.; CASTRO, R.S.; TABOSA, J.H.C. et al. Colheita do fluído brônquio-alveolar de bezerros através da traqueocentese transcutânea. Arq. Bras. Med. Vet. Zootec., v.46, p.41-49, 1994.

CORSTVET, R.E.; RUMMAGE, J.A.; HOMER, J.T. Recovery of pulmonary alveolar macrophages from nonanesthetized calves. Am. J. Vet. Res., v.43, p.22532254, 1982.

CRISMAN, M.V.; HODGSON, D.R.; BAYLY, W.M. et al. Effects of transport on constituents of bronchoalveolar lavage fluid from horses. Cornell Vet., v.82, p.233-246, 1992.

CURRLE, M. Endoskopische, tracheobronchialse kretzytologische und arterielle Blutgasuntersuchungen bei bronchopneumonie-kranken Rinder. 1985. 179f. Inaugural. Dissertation (Doctor Medicinae Veterinariae) Tierarztliche Hochschule Hannover.

DEEGEN, E.; MÜLLER, P.; PETZOLD, K Bronchoscopy and cytological examination of bronchial secretions of horses with chronic obstructive pulmonary disease (COPD). Poumon-Coeur, v.38, p.311-316, 1982.

DERKSEN, F.J.; BROWN, C.M.; SONEA, I. et al. Comparison of transtracheal aspirate and bronchoalveolar lavage cytology in 50 horses with chronic lung disease. Equine Vet. J., v.21, p.23-26, 1989.

GONÇALVES, R.C. Estudo da flora traqueobrônquica em bezerros clinicamente sadios e portadores de pneumonia, na região de Botucatu, SP. 1987. 44f. Dissertação (Mestrado) - Faculdade de Medicina Veterinária e Zootecnia, Universidade Estadual Paulista, Botucatu, SP.

GONÇALVES, R.C.; KUCHEMBUCK, M.R.G.; ALMEIDA, C.T. Lavagem traqueobrônquica por traqueocentese em bovinos. Vet. Zootec., v.2, p.17-25, 1990

HOFFMAN, A.M.; LAURENT, V.; STAEMPFLI, H.R. et al. Sensitivity and specificity of bronchoalveolar lavage and protected catheter brush methods for isolating bacteria from foal with experimentally induced pneumonia caused by Klebsiella pneumoniae. Am. J. Vet. Res., v.54, p.1803-1807, 1993.

JAIN, N.C. Essentials of veterinary hematology. Philadelphia: Lea \& Febiger, 1993. 417p.
KOSS, L.G. Diagnostic cytology and its histopathologic bases. 4.ed. Philadelphia: J.B. Lippincott, 1992. 2V.

LEID, R.W.; POTTER, K.A. Inflammation and mediators of lung injury. Vet. Clin. North Am.: Food Anim. Pract., v.1, p.377-400, 1985.

LESTER, G. Case presentation. Compend. Contin. Educ. Pract. Vet., v.15, p.737-741, 1993.

MANSMANN, R.A.; KNIGHT, H.D. Transtracheal aspiration in the horse. J. Am. Vet. Med. Assoc., v.160, p.1527, 1972.

McGORUM, B.C.; DIXON, P.M.; HALLIWELL, R.E.W. et al. Comparison of cellular and molecular components of bronchoalveolar lavage fluid harvest from different segments of the equine lungs. Res. Vet. Sci., v.55, p.57-59, 1993.

PRINGLE, J.K.; VIEL, L.; SHEWEN, P.E. et al. Bronchoalveolar lavage of cranial and caudal lung regions in selected normal calves: cellular, microbiological, immunoglobulin, serological and histological variables. Can. J. Vet. Res., v.52, p.239-248, 1988.

ROSZEL, J.F.; FREEMAN, K.P.; SLUSHER, S.H. Equine pulmonary cytology. In: ANNUAL CONVENTION OF THE AMERICAN ASSOCIATION OF EQUINE PRACTITIONERS, 31., 1986, Toronto. Proceedings... Toronto: American Association of Equine Practitioners, 1986. p.171-181.

SCOTT, P.R. Field study of undifferentiated respiratory disease in housed beef calves. Vet. Rec., v.134, p.325327, 1994.

SWEENEY, C.R.; HUMBER, K.A.; ROBY, K.A.W. Cytologic findings of tracheobronchial aspirates from 66 Thoroughbred racehorses. Am. J. Vet. Res., v.53, p.1172$1175,1992 \mathrm{a}$.

SWEENEY, C.R.; SMITH, J.A. Diseases of respiratory system. In: SMITH, B.P. Large animal internal medicine. St Louis: CV Mosby, 1990. V.1, cap.29, p.489-618.

SWEENEY, C.R.; SWEENEY-III, R.W.; BENSON, C.E. Comparison of bacteria isolated from specimens obtained by use of endoscopic guarded tracheal swabbing and percutaneous tracheal aspiration in horses. J. Am. Vet. Med. Assoc., v.195, p.1225-1229, 1989.

TAYLOR, G.; THOMAS, L.H.; STOTT, E.J. Effect of vaccination on cell populations in lung washes from calves after infection with respiratory syncytial virus. Res. Vet. Sci., v.47, p.231-235, 1989.

TORRES, W.L.N.; MORENO, G.; BOTTINO, J.A. et al. Estudo da eficácia do Obanol-516 na desinfecção em cirurgia. Rev. Med. Vet., v.6, p.140-150, 1970.

ZINKL, J.G. The Lower respiratory tract. In: COWELL, R.L.; TYLER, R.D. Cytology and hematology of the horse. California: American Veterinary Publications, 1992. Chap. 5, p.77-87. 